\title{
Trypanosoma cruzi: Infectivity of Clonal Genotype Infections in Acute and Chronic Phases in Mice
}

\author{
Marta de Lana, ${ }^{1}$ Artur da Silveira Pinto, ${ }^{2}$ Brigitte Bastrenta, Christian Barnabé, Sébastien Noël, \\ and Michel Tibayrenc \\ Centre d'Etudes sur le Polymorphisme des Microorganismes (CEPM), Unité Mixte de Recherche no. 9926 \\ Centre National de la Recherche Scientifique (CNRS)/Institut de Recherche pour le Développement (IRD), \\ B.P. 5045, 34032 Montpellier Cedex 1, France
}

Lana, M. de, Silveira Pinto, A. da, Bastrenta, B., Barnabé, C., Noël, S., and Tibayrenc, M. 2000. Trypanosoma cruzi: Infectivity of clonal genotype infections in acute and chronic phases in mice. Experimental Parasitology 96, 61-66. Eight Trypanosoma cruzi stocks pertaining to the clonal genotypes $19 / 20,32$, and 39 have been characterized for three experimental parameters of infectivity in Balb/c mice: (i) percentage of mice with a patent parasitemia (\% MPP), (ii) maximum parasitemia (MP), and (iii) percentage of mice with positive hemoculture $(\% \mathrm{MPH})$. By order of decreasing values, the values recorded for the clonal genotypes ranked as follows: 19/20, 32, and 39, except for the \% MPP parameter, for which $19 / 20$ and 32 were not statistically different. The rate of successful reisolation after infection in mice, analyzed by multilocus enzyme electrophoresis and random amplified polymorphic DNA typing, was statistically different according to the clonal genotype and was different for uniclonal infections and for mixed infections by two different clonal genotypes. These results confirm that T. cruzi clonal genotypes differ significantly in their infectivity in mice. (c) 2000 Academic Press

Index Descriptors and Abbreviations: Trypanosoma cruzi; phylogenetic divergence; clonal structure; biomedical variability; multilocus enzyme electrophoresis (MLEE); random amplified polymorphic DNA (RAPD).

\footnotetext{
${ }^{1}$ To whom reprint requests should be addressed at permanent address: Departamento de Análises Clínicas, Escola de Farmácia, Rua Costa Sena, 171, Universidade Federal de Ouro Preto, Ouro Preto, MG, Brazil, CEP 35.400-000.

${ }^{2}$ Permanent address: Departamento de Microbiologia, Instituto de Ciências Biológicas, CP 486, Universidade Federal de Minas Gerais, 31270-010, Belo Horizonte, MG, Brazil.
}

\section{INTRODUCTION}

As shown by population genetic analyses, the populations of Trypanosoma cruzi, the agent of Chagas' disease, are composed of natural clones, stable in space and time, between which recombination is either rare or absent (Tibayrenc et al. 1986). Previous studies by our group have shown that the phylogenetic diversity and the biological behavior of $T$. cruzi natural clones are statistically linked. Those clones that are phylogenetically distant tend to show very distinct properties for various biological parameters, including pathogenicity in mice, infectivity to cell cultures, speed of in vitro culture growth, in vitro sensitivity to antichagasic drugs, and transmissibility through Triatoma infestans, whereas the contrary obtains for those clones that are phylogenetically closely related (Laurent et al. 1997; Lana et al. 1998; Revollo et al. 1998). The goals of this study were to further explore the pathogenicity of $T$. cruzi natural clones in mice using an extended sample of clonal genotypes and to analyze with appropriate genetic markers the rate of successful reisolation of uniclonal and biclonal infections.

\section{MATERIALS AND METHODS}

Origin, culturing, and genetic characterization of parasites. Eight of the standardized set of 21 stocks used by our team for all studies 
TABLE 1

Stocks of Trypanosoma cruzi Analyzed

\begin{tabular}{|c|c|c|c|c|c|c|}
\hline \multirow[b]{2}{*}{ Name } & \multirow[b]{2}{*}{ Clonal genotype } & \multicolumn{2}{|c|}{ Number of infected mice } & \multirow[b]{2}{*}{ Host } & \multirow[b]{2}{*}{ Country } & \multirow[b]{2}{*}{ Region } \\
\hline & & Acute phase & Chronic phase & & & \\
\hline $\mathrm{SO} 34$ cl4 & $19 / 20$ & 7 & 5 & Triatoma infestans & Bolivia & Potosi \\
\hline Esquilo cl1 & $19 / 20$ & 8 & 6 & Sciurus aestuans & Brazil & Saõ Paulo \\
\hline SP104 cl1 & $19 / 20$ & 8 & 6 & Triatoma spinolai & Chile & Choquimbo \\
\hline $\mathrm{SO} 3 \mathrm{cl} 5$ & 39 & 8 & 5 & Triatoma infestans & Bolivia & Potosi \\
\hline MN cl2 & 39 & 8 & 5 & Man, chronic phase & Chile & Santiago \\
\hline $\mathrm{CBB} \mathrm{cl} 3$ & 32 & 8 & 6 & Man, chronic phase & Chile & Tulahuen \\
\hline MVB cl8 & 32 & 8 & 6 & Man, chronic phase & Chile & Santiago \\
\hline IVV cl4 & 32 & 8 & 6 & Man, chronic phase & Chile & Santiago \\
\hline
\end{tabular}

dealing with the biological behavior of $T$. cruzi natural clones were selected. These 21 stocks are representative of three major clonal lineages of T. cruzi (19/20, 32, and 39; Tibayrenc et al. 1986) and correspond to clonal genotypes that are spread over vast geographic areas. The evolutionary distances between these clonal genotypes are large. Nevertheless, 32 and 39 are more closely related to each other than to $19 / 20$, and both pertain to the same of the two major phylogenetic lineages that subdivide T. cruzi, whereas 19/20 falls into the other major phylogenetic lineage (Tibayrenc 1995; Souto et al. 1996).

The origin of the eight stocks under study is shown in Table 1, together with their clonal genotype and the number of mice inoculated and analyzed for each of them. The eight stocks have been previously typed with 22 enzyme loci (C. Barnabé, unpublished data) and RAPD fingerprinting (Tibayrenc et al. 1993). They have been cloned in the laboratory, with verification under the microscope. According to their behavior in mice, they have been used to compose 11 different mixtures to analyze the rate of survival of mixed infections. The clonal genotypes 19/20 and 32 were each represented by a "fast" stock (easily infective and more virulent to mice), a "slow" stock, and a "medium" stock. The clonal genotype 39 was represented by a "fast" and a "medium" stock only. Table 2 summarizes the composition of these mixtures and the number of mice inoculated and analyzed.
Purified metacyclic trypomastigote forms were obtained from old LIT medium cultures (15-20 days) after treatment with guinea pig serum according to Deane et al. (1984). Sets of seven to eight 30-dayold male Balb/c mice (weight $18-20 \mathrm{~g}$ ) were intraperitonally inoculated with these trypomastigotes. For infections with only one clone, $5 \times$ $10^{5}$ forms were used, whereas in the case of mixtures, $5 \times 10^{5}$ of each clone were injected. As a matter of fact, in our experience, biclonal infections with a lower quantity of each pure clone can lead to very fast elimination of one of the genotypes.

During the acute phase of the infection, mice were monitored every day for parasitemia and mortality. The parasitemia was quantified according to Brener (1962). Thirty days after infection, a volume of approximately $500 \mu \mathrm{l}$ of blood was taken from each mouse through the orbital plexus vein and inoculated in LIT medium. Of 86 mice, 36 positive cultures were obtained. These cultures were used to look for the presence of given genotypes by multilocus enzyme electrophoresis (MLEE) and RAPD typing. Five isoenzyme systems (glucose phosphate isomerase, GPI, E.C.5.3.1.9; glutamate oxaloacetate transaminase, GOT, E.C.2.6.1.1; isocitrate dehydrogenase, ICD, E.C.1.1.1.42; phosphoglucomutase, PGM, E.C.5.4.2.2; and 6 phosphogluconate dehydrogenase, 6PGD, E.C.1.1.1.44) and two RAPD primers (A7:

TABLE 2

Composition of the Mixtures of Trypanosoma cruzi Natural Clones Analyzed

\begin{tabular}{|c|c|c|c|c|}
\hline \multirow[b]{2}{*}{ Genotype mixture } & \multirow[b]{2}{*}{ Stock mixture } & \multicolumn{2}{|c|}{ Number of infected mice } & \multirow[b]{2}{*}{ Category of mixture } \\
\hline & & Acute phase & Chronic phase & \\
\hline $19 / 20+32$ & Esquilo cl1 + MVB cl8 & 8 & 6 & Medium + medium \\
\hline $19 / 20+32$ & $\mathrm{SO} 34 \mathrm{cl} 4+\mathrm{CBB} \mathrm{cl} 3$ & 8 & 6 & Fast + fast \\
\hline $19 / 20+32$ & SP104 cl1 + IVV cl4 & 8 & 6 & Slow + slow \\
\hline $19 / 20+32$ & SP104 cl1 + CBB cl3 & 8 & 6 & Slow + fast \\
\hline $19 / 20+32$ & SO34 cl4 + IVV cl4 & 7 & 5 & Fast + slow \\
\hline $19 / 20+39$ & Esquilo cl1 $+\mathrm{MN} \mathrm{cl3}$ & 8 & 6 & Medium + medium \\
\hline $19 / 20+39$ & $\mathrm{SO} 34 \mathrm{cl} 4+\mathrm{SO} 3 \mathrm{cl} 5$ & 8 & 6 & Fast + fast \\
\hline $19 / 20+39$ & $\mathrm{SP} 104 \mathrm{cl} 1+\mathrm{SO} 3 \mathrm{cl} 5$ & 7 & 5 & Slow + fast \\
\hline $32+39$ & MVB c18 + MN cl2 & 8 & 6 & Medium + medium \\
\hline $32+39$ & $\mathrm{CBB} \mathrm{cl} 3+\mathrm{SO} 3 \mathrm{cl} 5$ & 8 & 6 & Fast + fast \\
\hline $32+39$ & IVV cl4 + SO3 cl5 & 8 & 6 & Slow + fast \\
\hline
\end{tabular}


GAAACGGGTG; and A10: GTGATCGCAG; kit A from Operon Technologies, Alameda, CA) were used. Technical parameters were as published (Ben Abderrazak et al. 1993; Tibayrenc et al. 1993).

At 90 days after infection (chronic phase), the mice that were still alive were sacrified. Hemocultures were performed. Twenty-five isolates of 64 hemocultures were obtained and genetically characterized, as described above.

Data analysis. During the acute phase of infection, three parameters were quantified: (i) the percentage of mice with a patent parasitemia (\% MPP), (ii) the maximum parasitemia (MP), and (iii) the percentage of mice with positive hemoculture (\% MPH). For the uniclonal infections, 63 mice were examined (7-8 per stock; see Table 1). For the biclonal infections (11 different mixtures; see Table 2), a total of 86 mice were examined (again 7-8 per mixture). During the chronic phase of the infection, only \% MPH was quantified for the surviving animals (5-6 per group). A total of 45 mice for the uniclonal infections and 64 mice for the biclonal infections was considered in this part of the experiments.

For each of the three pure clonal genotypes, the value considered for each of the three parameters under study was the arithmetic mean of all the available results. In the case of the parameters \% MPP and $\% \mathrm{MPH}$, comparisons of percentages were used, whereas comparisons of means were used for MP. We compared the values obtained for the pure clone of two different genetic groups. Comparisons between uniclonal and biclonal infections were rendered tentative by the fact that the total amount of parasites injected was not the same.

\section{RESULTS}

Acute phase. For the two parameters MP and \% MHP, there were statistically significant differences between the three clonal genotypes, in the order 19/20 > 32 > 39. For the parameter \% MPP, the decreasing order was $32>19 /$ $20>39$. Nevertheless, the difference between 32 and 19/ 20 was not statistically significant (see Tables 3 and 4).

Chronic phase. The only parameter surveyed in this phase was \% MPH. The order of decreasing values was $19 / 20>32>39$. Nevertheless, the differences were not statistically significant.

\section{TABLE 3}

Average Results Obtained for the Three Parameters Surveyed for the Pure Clonal Genotypes

\begin{tabular}{ccccc}
\hline \multirow{5}{c}{ Parameter } \\
\cline { 2 - 5 } Group & \% MPP & MP & \% MPH ap & \% MPH cp \\
\hline $19 / 20$ & 43.48 & $26.99 \pm 59.98$ & 100.00 & 94.12 \\
32 & 62.50 & $1.04 \pm 2.49$ & 79.17 & 72.22 \\
39 & 0.00 & $0.00 \pm 0.00$ & 12.50 & 70.00 \\
\hline
\end{tabular}

Note. ap, acute phase; $\mathrm{cp}$, chronic phase.
TABLE 4

Statistical Results of the Various Comparisons Performed between Pure Clonal Genotypes

\begin{tabular}{rcccc}
\hline & \multicolumn{4}{c}{ Parameter } \\
\cline { 2 - 5 } Comparison & \%PP & MP & \% MPH ap & \% MPH cp \\
\hline $19 / 20$ to 32 & NS & $<0.05$ & $<0.05$ & NS \\
$19 / 20$ to 39 & $<0.01$ & $<0.04$ & $<0.01$ & NS \\
32 to 39 & $<0.01$ & $<0.04$ & $<0.01$ & NS \\
\hline
\end{tabular}

Note. ap, acute phase; $\mathrm{cp}$, chronic phase.

Survival of uniclonal and biclonal infections surveyed by MLEE and RAPD. Table 5 (see also Figs. 1 and 2) gives the results of $T$. cruzi stock typing after infection. About $30 \%$ of the biclonal infections (all mixtures plotted together) were still detected at both the acute and the chronic phases of infection. In only one mouse was the biclonal infection (Esquilo cl1 + MVB cl8) detected in both acute and chronic phases of the infection. On the other hand, the survival of the mixture $19 / 20+32$ appeared to be better than both 19/ $20+39$ and $32+39$. Nevertheless, the difference was not statistically significant, as verified by $\chi^{2}$ or Yates' corrected $\chi^{2}$. Last, the survival of uniclonal infections was different according to the clonal genotype: 32, then 19/20, then 39 for the acute phase; 19/20, then 32 , then 39 for the chronic phase. Nevertheless, only the comparisons $19 / 20$ vs 39 and 32 vs 39 for the acute phase and 19/20 vs 39 for the chronic phase were statistically significant, as verified by either $\chi^{2}$ or Yates' corrected $\chi^{2}\left(P<10^{-2},<10^{-3},<10^{-2}\right.$, respectively).

\section{DISCUSSION}

In this study of infection in mice, the behavior of the three clonal genotypes 19/20,32, and 39 in uniclonal infections is roughly similar to that in other studies which surveyed other experimental parameters (Laurent et al. 1997; Lana et al. 1998; Pinto et al. 1998; Revollo et al. 1998). There is a broad range of values from one stock to another for the three parameters of infectivity surveyed here. Nevertheless, when the stocks pertaining to different clonal genotypes are compared, there are statistically significant differences between clonal genotypes. The only exception was between 19/20 and 32 for the \% MPP parameter. This confirms that for infectivity in mice too, clonal diversity has an impact on the biological behavior of $T$. cruzi stocks. 
TABLE 5

Quantitative Results of Monoclonal and Mixed Infections Detected in Mice by MLEE and RAPD during the Acute and Chronic Phases of the Infection

\begin{tabular}{|c|c|c|c|c|c|}
\hline Marker & Mixture & $\begin{array}{l}\text { Acute phase } \\
\text { mixed infection }\end{array}$ & $\begin{array}{l}\text { Chronic phase } \\
\text { mixed infection }\end{array}$ & $\begin{array}{l}\text { Acute phase } \\
\text { pure clone }\end{array}$ & $\begin{array}{l}\text { Chronic phase } \\
\text { pure clone }\end{array}$ \\
\hline & & & & 19/20: $2 / 15(0.13)$ & 19/20: 7/14 (0.50) \\
\hline \multirow[t]{2}{*}{ MLEE } & & $7 / 15(0.47)$ & $5 / 14(0.36)$ & 32: $6 / 15(0.40)$ & 32: $2 / 14(0.14)$ \\
\hline & & & & 19/20: $3 / 15(0.20)$ & 19/20: 6/13 (0.46) \\
\hline \multirow[t]{2}{*}{ RAPD } & $19 / 20+32$ & $6 / 15(0.40)$ & $2 / 13(0.15)$ & 32: $6 / 15(0.40)$ & 32: $4 / 13(0.31)$ \\
\hline & & & & 19/20: $2 / 15$ & $19 / 20(4 / 13)$ \\
\hline \multirow[t]{2}{*}{ MLEE + RAPD } & & $7 / 15(0.47)$ & $7 / 13(0.54)$ & $32: 6 / 15$ & $32(2 / 13)$ \\
\hline & & & & 19/20: 10/11 (0.91) & 19/20: $8 / 8$ \\
\hline \multirow[t]{2}{*}{ MLEE } & & $0 / 11$ & $0 / 8$ & 39: $0 / 11$ & 39: $0 / 8$ \\
\hline & & & & 19/20: 9/11 (0.82) & 19/20: $8 / 8$ \\
\hline \multirow[t]{2}{*}{ RAPD } & $19 / 20+39$ & $1 / 11(0.09)$ & $0 / 8$ & 39: $1 / 11(0.09)$ & 39: $0 / 8$ \\
\hline & & & & 19/20: 9/11 (0.82) & 19/20: $8 / 8$ \\
\hline \multirow[t]{2}{*}{ MLEE + RAPD } & & $2 / 11(0.18)$ & $0 / 8$ & 39: $1 / 11(0.09)$ & 39: $0 / 8$ \\
\hline & & & & $32: 10 / 10$ & $32: 3 / 3$ \\
\hline \multirow[t]{2}{*}{ MLEE } & & $0 / 10$ & $0 / 3$ & 39: $0 / 10$ & $39: 0 / 3$ \\
\hline & & & & 32: $9 / 10(0.90)$ & $32: 3 / 3$ \\
\hline \multirow[t]{2}{*}{ RAPD } & $32+39$ & $1 / 10(0.10)$ & $0 / 3$ & 39: $0 / 10$ & $39: 0 / 3$ \\
\hline & & & & $32: 9 / 10(0.90)$ & $32: 3 / 3$ \\
\hline \multirow{3}{*}{ MLEE + RAPD } & & $1 / 10(0.10)$ & $0 / 3$ & 39: $0 / 10$ & $39: 0 / 3$ \\
\hline & & & & 19/20: $12 / 26(0.46)$ & 19/20: $12 / 21(0.57)$ \\
\hline & & & & $32: 15 / 25(0.60)$ & $32: 5 / 16(0.32)$ \\
\hline MLEE + RAPD & Total & $10 / 36(0.28)$ & $8 / 25(0.32)$ & $39: 1 / 21(0.05)$ & 39: $0 / 11$ \\
\hline
\end{tabular}

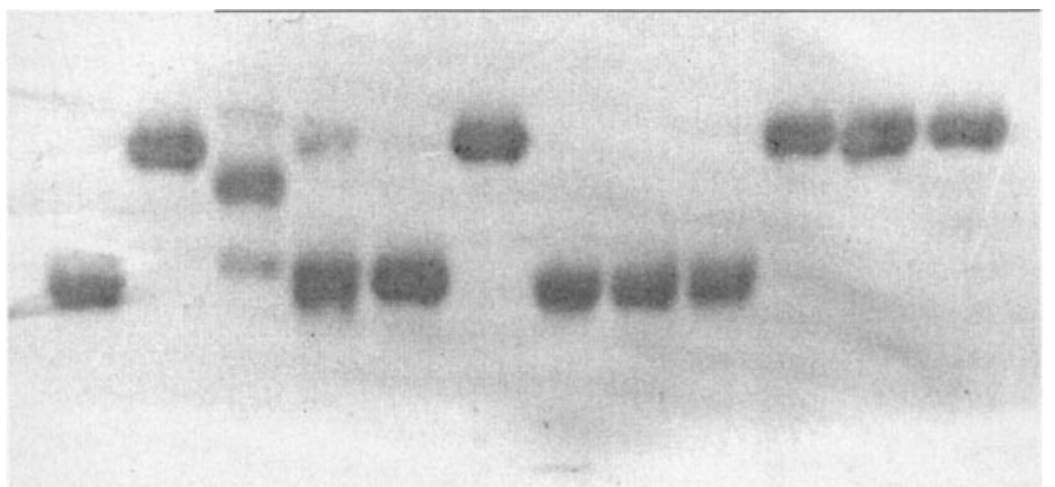

\section{$\begin{array}{llllllllllll}1 & 2 & 3 & 4 & 5 & 6 & 7 & 8 & 9 & 10 & 11 & 12\end{array}$}

FIG. 1. Isoenzyme profiles revealed with the glucose phosphate isomerase system in Trypanosoma cruzi cultures obtained from Balb/C mice exposed to biclonal T. cruzi infection during the chronic phase of the infection. Lane 1, genotype 19/20 (uniclonal infection); lane 2, genotype 32 (uniclonal infection); lane 3, genotype 39 (uniclonal infection); lanes 4-6, 19/20 +32 genotypes (biclonal infections); lane 4 shows the mixture of genotypes, whereas lanes 5 and 6 show only the genotypes 19/20 and 32, respectively; lanes 7-9, 19/20 + 39 genotypes (biclonal infections); only the 19/20 genotypes are visible; lanes 10-12, $32+39$ genotypes (biclonal infections); only the 32 genotypes are visible. 


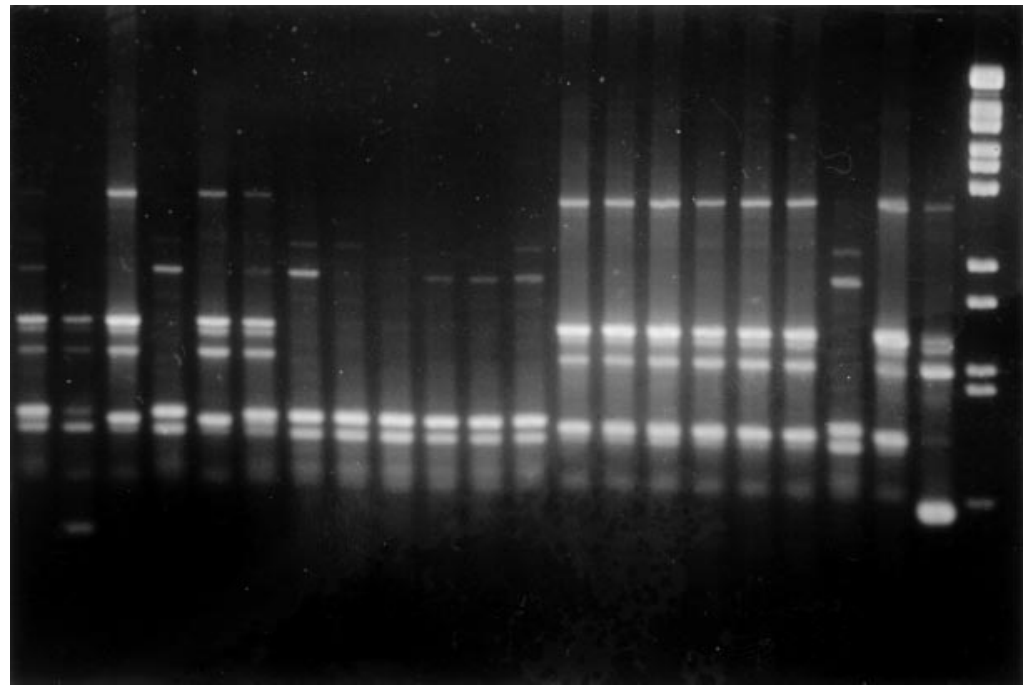

\section{2}

FIG. 2. Random amplification of polymorphic DNA with the A10 primer in samples obtained from Balb/C mice inoculated with biclonal Trypanosoma cruzi populations, attributed to the 19/20, 32, and 39 genotypes, during the acute and chronic phases of the infection. Lanes 1-3, $19 / 20+32$ genotypes; biclonal infection (acute phase); lanes 1 and 2 show the mixture, whereas lane 3 shows only genotype 32; lanes 4-6, 19/ $20+32$ genotypes; biclonal infection (chronic phase); lane 6 shows the mixture, whereas lanes 4 and 5 show only genotypes 19/20 and 32, respectively; lanes 7-9, 19/20 + 39 genotypes; biclonal infection (acute phase); only the genotype 19/20 is visible; lanes 10-12, 19/20 + 39 genotypes; biclonal infection (chronic phase); only the genotype 19/20 is visible; lanes 13-15, $32+39$ genotypes; biclonal infection (acute phase); only the genotype 32 is visible; lanes $16-18,32+39$ genotypes; biclonal infection (chronic phase); only the genotype 32 is visible; lane 19 , genotype 19/20; uniclonal infection; lane 20, genotype 32; uniclonal infection; lane 21, genotype 39; uniclonal infection; lane 22, scale ladder.

The possibility of reisolating a given stock during the course of mice infection tends to be different when different clonal genotypes are considered (Table 5). The clonal genotype 39 seems to be more easily controlled by the immune defenses of the organism than both 32 and 39. Therefore, there tends to be a link between the results obtained for the three parameters surveyed here and the rate of successful reisolation. The mixtures involving this clonal genotype (either $19 / 20+39$ or $32+39$ ) show also a lower rate of successful reisolation than the mixture $19 / 20+32$, although this is not confirmed by statistical verification. Only one mixture was isolated in both the acute and the chronic phases of the infection.

\section{ACKNOWLEDGMENTS}

This work was supported by the WHO Special Programme for Research and Training in Tropical Diseases (No. 910268), an EEC STD3 Grant No. TS3* CT92-0155, and a Groupement de Recherche
Grant CNRS/French Army. Dra. Marta de Lana and Dr. Artur. da S. Pinto were supported by fellowships from Conselho Nacional do Desenvolvimento Científico e Tecnológico (CNPq), Brazil.

\section{REFERENCES}

Ben Abderrazak, S., Guerrini, F., Mathieu-Daudé, F., Truc, P., Neubauer, K., Lewicka, K., Barnabé, C., and Tibayrenc, M. 1993. Isozyme electrophoresis for parasite characterization. In "Protocols in Molecular Parasitology” (J. E. Hyde, Ed.), pp. 361-382. Humana Press, Totowa, NJ.

Brener, Z., 1962. Therapeutic activity and criterion of cure in mice experimentally infected with Trypanosoma cruzi. Revista do Instituto de Medicina Tropical de São Paulo 39, 389-396.

Deane, M. P., Moriearty, P. L., and Thomaz, N. 1984. Genes and other parasitic protozoa. In "Genes and Antigens of Parasites: A Laboratory Manual (C. M. Morel, Ed.), 2nd ed., pp. 11-21. Fundação Oswaldo Cruz, Rio de Janeiro, Brazil.

Lana, M., Pinto, A, da, S., Barnabé, C., Quesney, V., Noël, S., and 
Tibayrenc, M. 1998. Trypanosoma cruzi: Compared vectorial transmissibility of 3 major clonal genotypes by Triatoma infestans. Experimental Parasitology 90, 20-25.

Laurent, J. P., Barnabé, C., Quesney, V., Noël, S., and Tibayrenc, M. 1997. Impact of clonal evolution on the biological diversity of Trypanosoma cruzi. Parasitology 114, 213-218.

Pinto, A. da S., de Lana, M., Bastrenta, B., Barnabé, C., Quesney, V., Noël, S., and Tibayrenc, M. 1998. Compared vectorial transmissibility of pure and biclonal clonal genotypes of Trypanosoma cruzi in Triatoma infestans. Parasitology Research 84, 348-353.

Revollo, S., Oury, B., Laurent, J. P., Barnabé, C., Quesney, V., Carrière, V., Noël, S., and Tibayrenc, M. 1998. Trypanosoma cruzi: Impact of clonal evolution of the parasite on its biological and medical properties. Experimental Parasitology 89, 30-39.

Souto, R. P., Fernandes, O., Macedo, A. M., Campbell, D. A., and
Zingales, B. 1996. DNA markers define two major phylogenetic lineages of Trypanosoma cruzi. Molecular and Biochemical Parasitology 83, 141-152.

Tibayrenc, M. 1995. Population genetics of parasitic protozoa and other microorganisms. Advances in Parasitology 36, 47-115.

Tibayrenc, M., Neubauer, K., Barnabé, C., Guerrini, F., Sarkeski, D., and Ayala, F. J. 1993. Genetic characterization of six parasitic protozoa: Parity of random-primer DNA typing and multilocus isoenzyme electrophoresis. Proceedings of the National Academy of Sciences USA 90, 1335-1339.

Tibayrenc, M., Ward, P., Moya, A., and Ayala, F. J. 1986. Natural populations of Trypanosoma cruzi, the agent of Chagas' disease, have a complex multiclonal structure. Proceedings of the National Academy of Sciences USA 83, 115-119.

Received 23 April 1999; accepted with revision 19 July 2000 